\title{
Morphological Features of the Hypophyseal Intermediate Lobe Directly Related to its Activity*
}

\author{
William H. Boyd
}

Received September 20, 1971

\begin{abstract}
Summary. The bovine hypophysis serves as an excellent model for studying salient gross anatomical and microscopic features relative to the activity of the intermediate lobe.

A potential space between the anterior and intermediate lobe is converted into an intraglandular lumen during the cyclic behavior of the intermediate lobe. The cyclic behavior of the lobe is exhibited by 3 phases of cellular activity: 1) resting, 2) desquamation and autolysis, 3) regeneration. During the second phase, the marginal zone of intermediate lobe cells increase in size from $0.3 \mu$ to $10 \mu$ in diameter. As these cells autolyze, they break away from the deep zone thus giving rise to an intraglandular lumen. Within the lumen, the desquamated cells undergo further autolysis resulting in the formation of colloid, the breakdown product of marginal intermediate lobe cells.

As the intermediate lobe re-establishes itself by direct division of its remaining cells, the colloid is expelled from the intraglandular lumen into the venous cavernous sinuses by way of well defined capsular clefts.
\end{abstract}

Although recent reports show a renewed interest in the hypophyseal intermediate lobe (Romieu et al., 1951; Arvy and Du Borsson, 1961; BAlogh and Cohen, 1962; Pearse and van Noorden, 1963; Howe and Thody, 1967; Raftery, 1969; Gosbee et al., 1970) none present a critical study in a large series of normal animals, relative to the more salient microscopic and gross anatomical features which give some indication of intermediate lobe activity.

Relevant literature presents two anatomical factors which strongly suggest a direct bearing on intermediate lobe activity. First, a well established event reported by earlier workers (Lewis et al., 1911; RASMUSSEN, 1928; BRANDER, 1931) is the production of intraglandular (residual lumen) colloid, a feature common to all pituitary glands exhibiting three lobes. Even in this light, reports on experimental studies utilizing hypertonic saline to initiate intermediate lobe activity (SELYE, 1943; DUCHEN, 1962; Soboleva, 1964; Kastin, 1967; Howe and Thody, 1967) present different interpretations of the origin and significance of intraglandular colloid. Second, BRANDER's (1931) unconfirmed studies on the hypophysis in the human subject in which he recognized intraglandular colloid, suggests that the colloid finds its way into the "peri-hypophyseal blood space" by way of "breaches" in the capsule of the hypophysis. Indeed, BRANDER recognized this as a "novel physiological concept" and if confirmed "may modify our interpretation of the physiological, biochemical, clinical and pathological" understanding of the gland.

The present investigation began 6 years ago as a comparative anatomical study of the pituitary gland in the human subject, monkey, rat, dog, cat, rabbit and cow.

*This study was supported by grants from the Medical Research Council of Canada, the National Research Council of Canada, and the Banting Research Foundation (Toronto). 
Owing to its large size, the bovine hypophysis is utilized as a model. The bovine hypophysis clearly demonstrates salient anatomical features common to all the glands studied.

This paper makes specific reference to the origin and production of intraglandular colloid, the development of the intraglandular lumen and the passage of colloid from the intraglandular lumen to the venous cavernous sinuses by way of well defined clefts in the capsule of the gland. Thus the objectives of this report is to direct attention to features which are less readily understood, and have not been recognized, heretofore, as those having a direct bearing on intermediate lobe activity.

\section{Material and Methods}

The bovine hypophysis from 1100 two year old steers and heifers were studied. The glands were collected within 10 to 20 min after slaughter, fixed in either Bouin's solution or $10 \%$ formalin, and prepared in the usual manner for microscopic examination. The glands were sectioned at $3-5 \mu$ in either the sagittal, coronal or in the transverse plane. The sections were stained with either hematoxylin-eosin, Masson's trichrome stain or by means of the acid fuchsin-aniline blue method for pituitary granules. In addition, the surface anatomy of 250 fresh glands as well as thinly cut gross sections from a similar number of glands were studied with the aid of the dissecting microscope. Gross sections were stained with a mixture of acid fuschsin and methylene blue.

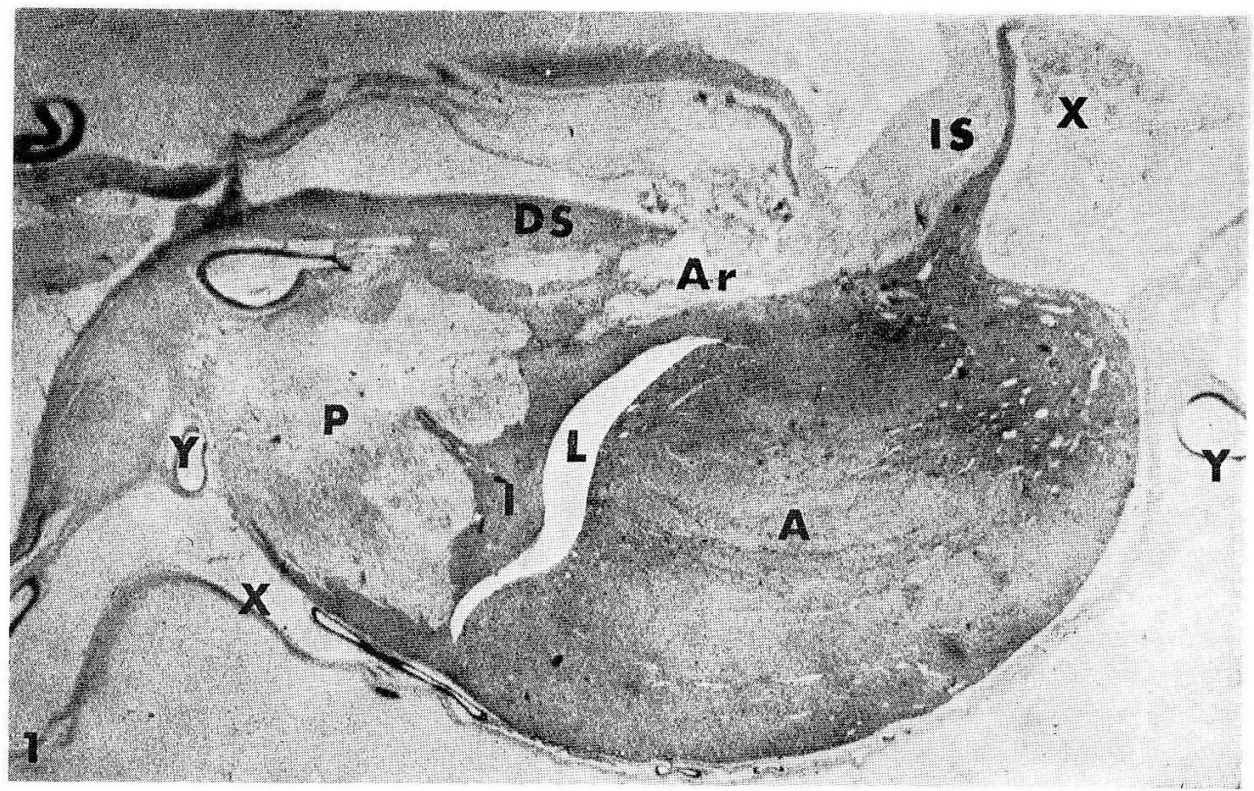

Fig. 1. Photomicrograph of the bovine hypophysis sectioned at $10 \mu$ and stained with a mixture of acid fuchsin and methylene blue. The distribution of the intermediate lobe is well demonstrated. Colloid has dropped out of the intraglandular lumen during sectioning leaving this area patent. Note how the arachnoid continues into the intermediate lobe. $A$ anterior lobe, $A r$ arachnoid, $D S$ diaphragma sella, $I$ intermediate lobe, IS infundibular stem, $L$ intraglandular lumen, $P$ posterior lobe. $X-X$ direction in which the gross section was cut in Figure 2. $Y \cdot Y$ direction in which the gross section was cut in Figure $3 . \times 35$ 
Organotypic cultures of intermediate lobe tissue were studied. Thirty fresh bovine glands were collected within 10 min after slaughter and placed in Tyrode's solution. The glands, covered in a dense fibrous capsule were rinsed in several changes of this solution and then cut mid-sagittally into two halves. The intermediate lobe was readily discernible and tissue was gathered aseptically by carefully dissecting it from the rostral surface of the posterior lobe.

Intermediate lobe tissue from each gland was minced separately into fine particles $\left(1 / 4 \mathrm{~mm}\right.$ or less). The particles were gathered into blocks $3-5 \mathrm{~mm}^{3}$, placed in a specially designed culture dish (unpublished data)and incubated at $37^{\circ} \mathrm{C}$ for 7 days. The culture media contained H597 (Connaught Medical Research Laboratories, Toronto, Canada). In addition, non-cultured intermediate lobe tissue from each gland was used as controls. All tissues were prepared for microscopic study in the usual manner, cut at 3-5 $\mu$ and stained with either hematoxylin-eosin or with Masson's trichrome stain.

\section{Results}

The bovine hypophyseal intermediate lobe is an "S" shaped structure (Fig. 1) abutting the posterior lobe and sending "finger-like" projections for variable distances into its substance. The lower and caudal pole of the intermediate lobe completely encapsulates the lower one half of the posterior lobe, while the upper and rostral pole
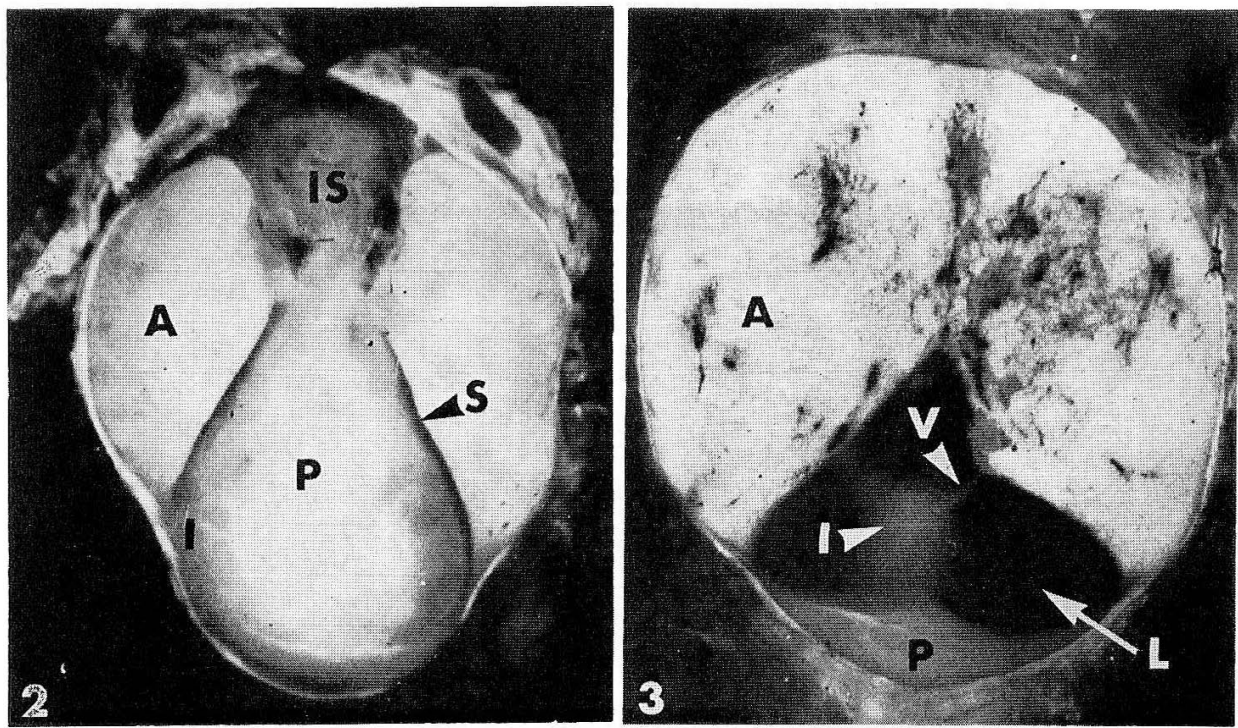

Fig. 2. Gross transverse section (See Fig. 1. $X-X$ ) through the bovine hypophysis stained with a mixture of acid fuchsin and methylene blue. The anterior and the intermediate lobe are directly opposed for the gland is in the resting phase. A anterior lobe, $I$ intermediate lobe, IS infundibular stem, $P$ posterior lobe, $S$ region of the potential space. $\quad \times 20$

Fig. 3. Gross transverse section (See Fig. 1. $Y-Y$ ) through the bovine hypophysis stained with a mixture of acid fuchsin and methylene blue. The newly formed intraglandular lumen is engorged with colloid and only a portion of the intermediate lobe is present. Note blood vessels spanning the lumen between the intermediate lobe and the anterior lobe. $A$ anterior lobe, $I$ intermediate lobe, $L$ intraglandular lumen, $\quad V$ blood vessels. $\quad \times 20$ 
forms the floor of a well-developed recess below the diaphragma sella. The arachnoid membrane fills the recess and under the light microscope, the membrane appears to continue into the tissue of the intermediate lobe (Fig. 1) with no intervening limiting membrane. Hollowed out cords of intermediate lobe cells, some filled with a colloid-like mass, are prevalent in this region. The intermediate lobe is separated from the caudal border of the anterior lobe by a potential space (Fig. 2). The lower $1 / 5$ of the space remains patent and may open directly upon the hypophyseal capsule covering the base of the gland. Where the anterior and the intermediate lobes are directly opposed, the caudal border of the anterior lobe is lined by a well-defined layer of cuboidal to columnar shaped cells resting upon abasement membrane. This is not true of the intermediate lobe for its rostral border is made up of the cells in the marginal portion of this lobe. This is in keeping with the cyclic activity of the intermediate lobe making it impossible for a definitive lining membrane to develop. Gross sections of the gland show that the intermediate lobe is either in direct contact with the anterior lobe or separated from it by a colloid filled intraglandular lumen. The vasculature of the gland can be dispensed with first. The intermediate lobe maintains a slight vascular communication with the posterior lobe by way of finger-like projections of intermediate lobe cells into the posterior lobe. Serial microscopic sections show that blood vessels develop from vascular buds originating in the intermediate lobe, and grow into the anterior lobe when the lobes are closely approximated. At this time the intermediate lobe is richly supplied with blood. With the
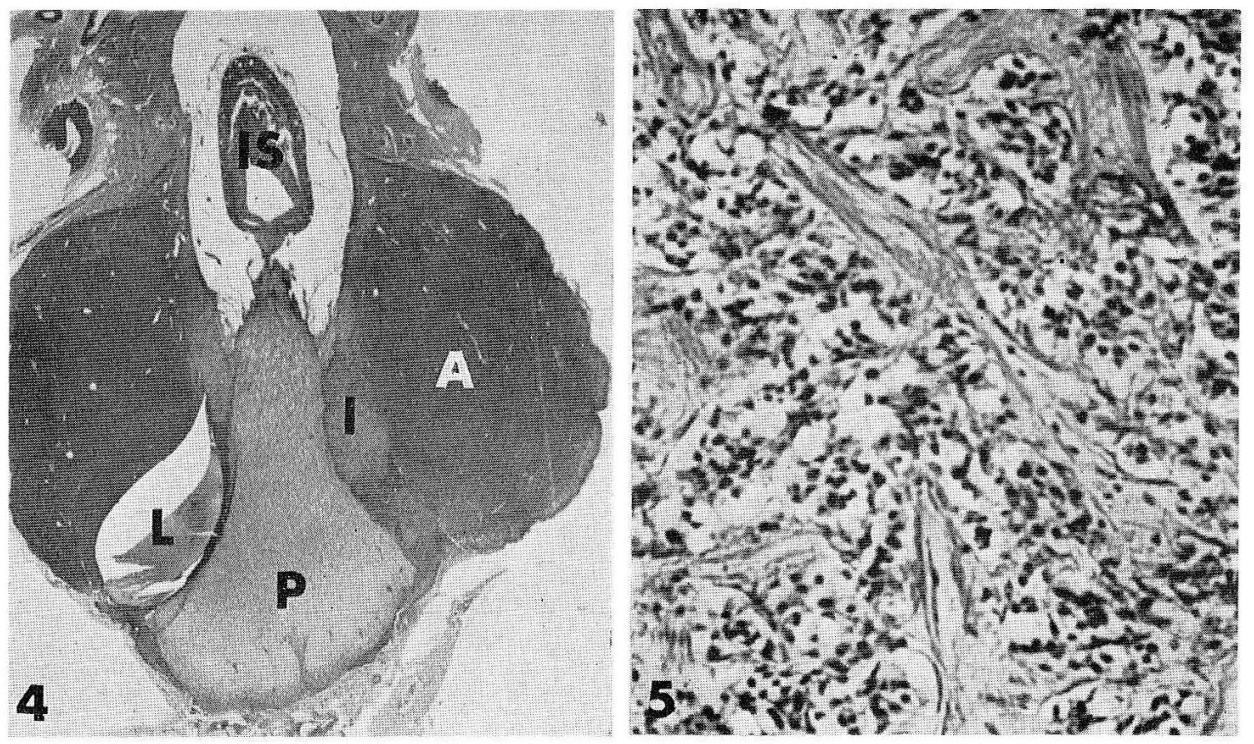

Fig. 4. Photomicrograph of the bovine hypophysis sectioned at $10 \mu$ and stained with a mixture of acid fuchsin and methylene blue. Note that the intraglandular lumen containing some colloid is well developed to the left of the posterior lobe while the intermediate and anterior lobe are directly opposed to the right of the posterior lobe. A anterior lobe, $I$ intermediate lobe, IS infundibular stem, $L$ intraglandular lumen, $P$ posterior lobe. $\quad \times 20$

Fig. 5. Photomicrograph of a section taken from the bovine hypophyseal intermediate lobe during the resting phase. The section is cut at $5 \mu$ and stained with Masson's trichrome. The distribution of cells is interrupted by fibrous bands placing the cells within pockets. $\quad \times 275$ 
development of a variable sized lumen or intraglandular lumen (Fig. 3, 4), welldemonstrable vascular connections are observed (Fig. 3) spanning the region between the anterior and intermediate lobe. The vascular relationship between the anterior and intermediate lobe breaks down with further development of the colloid-filled intraglandular lumen. For this reason blood cells may be found in the intraglandular colloid. Under these conditions, the intermediate lobe gives the appearance of being rather avascular.

Concerning the cyclic or periodic activity of the bovine intermediate lobe, the present study establishes the fact that there is no associated seasonal variation for the glands were collected from the slaughter house throughout the year and evidence of the cyclic nature of the intermediate lobe could always be demonstrated. Usually 10-12 glands were studied at one time.

The cyclic behavior of the lobe is indeed a unique feature. In general, the basis for this behavior can be found in the following events. Microscopically when the intermediate lobe is in direct contact with the anterior lobe, the cells are darkly stained, no mitotic figures are observable and the lobe is fairly well vascularized. The microscopic picture changes when autolysis and desqaumation of intermediate lobe cells heralds the development of an intraglandular lumen. The intermediate lobe can be divided into a marginal zone of large, lightly stained cells filled with cytoplasmic vacuoles while the deep layer of darkly stained cells undergo direct division. In the present study, the marginal zone of the intermediate lobe is the
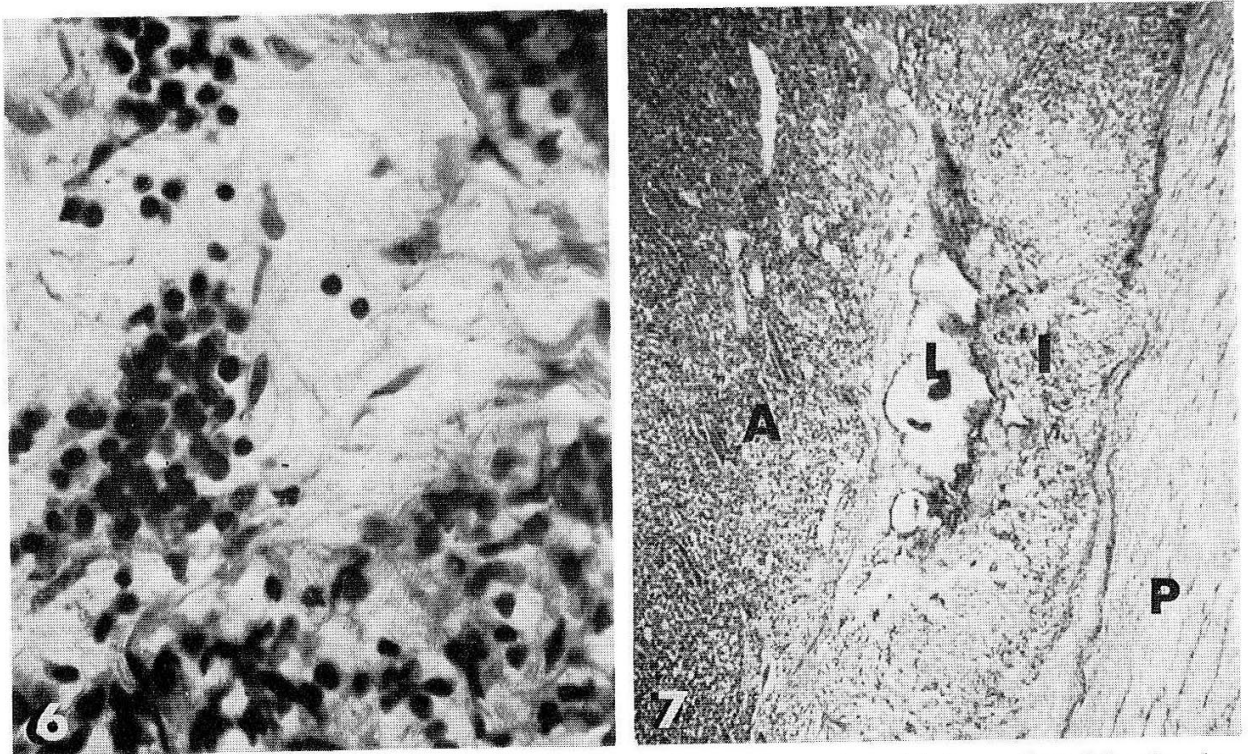

Fig. 6. Photomicrograph of a section taken from the bovine hypophyseal intermediate lobe showing the projection of arachnoid tissue into the intermediate lobe. The section is cut at $5 \mu$ and stained with Masson's trichrome. $\times 350$

Fig. 7. Photomicrograph of a section taken through the bovine hypophyseal intermediate lobe at the onset of phase 2, desquamation and autolysis. This shows the beginning of the development of the intraglandular lumen. A comparison of the walls of the lumen shows highly active cells covering the intermediate lobe. The section is cut at $5 \mu$ and stained with hematoxylin-eosin. $\times 100$ 


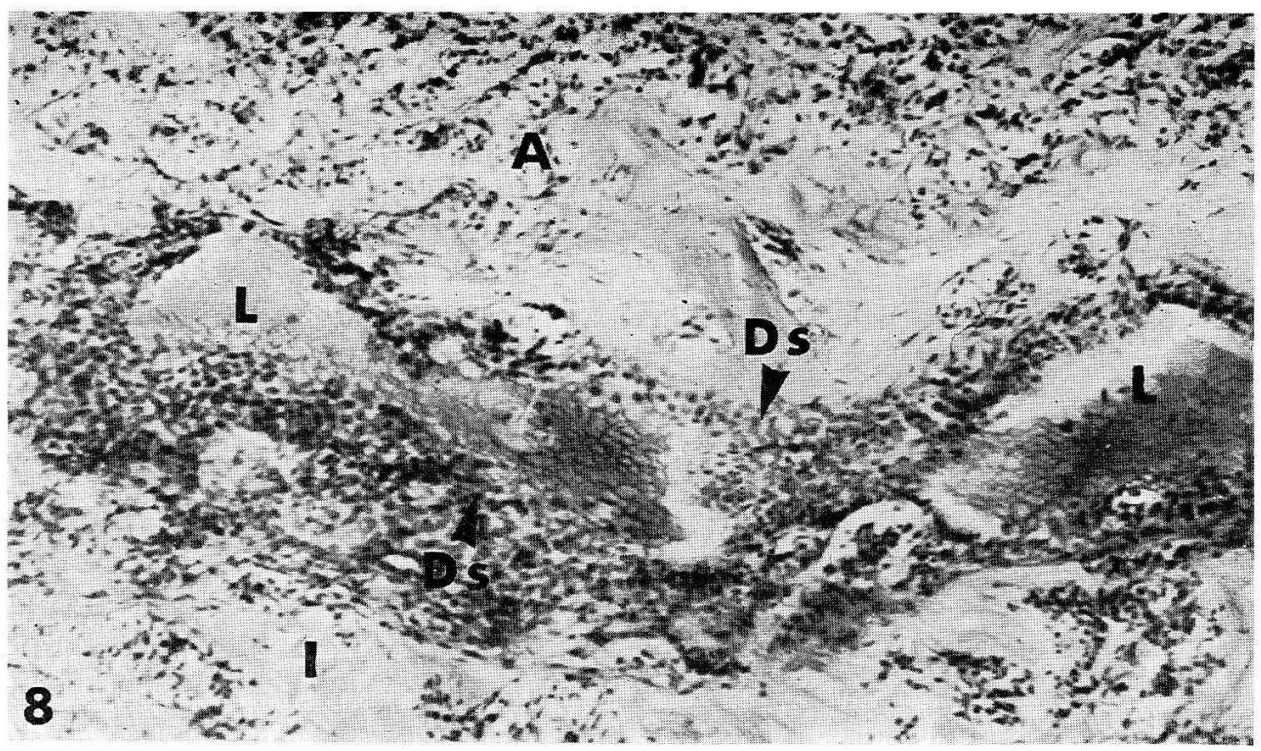

Fig. 8. Photomicrograph of a section through the bovine hypophysis showing the break-down of the marginal zone of the intermediate lobe and the desquamation of its cells converting the potential space between the lobes into an intraglandular lumen. The tissue was cut at $5 \mu$ and stained with hematoxylin-eosin. A anterior lobe, $D$ s desquamating intermediate lobe cells, $I$ intermediate lobe, $L$ intraglandular lumen. $\times 250$

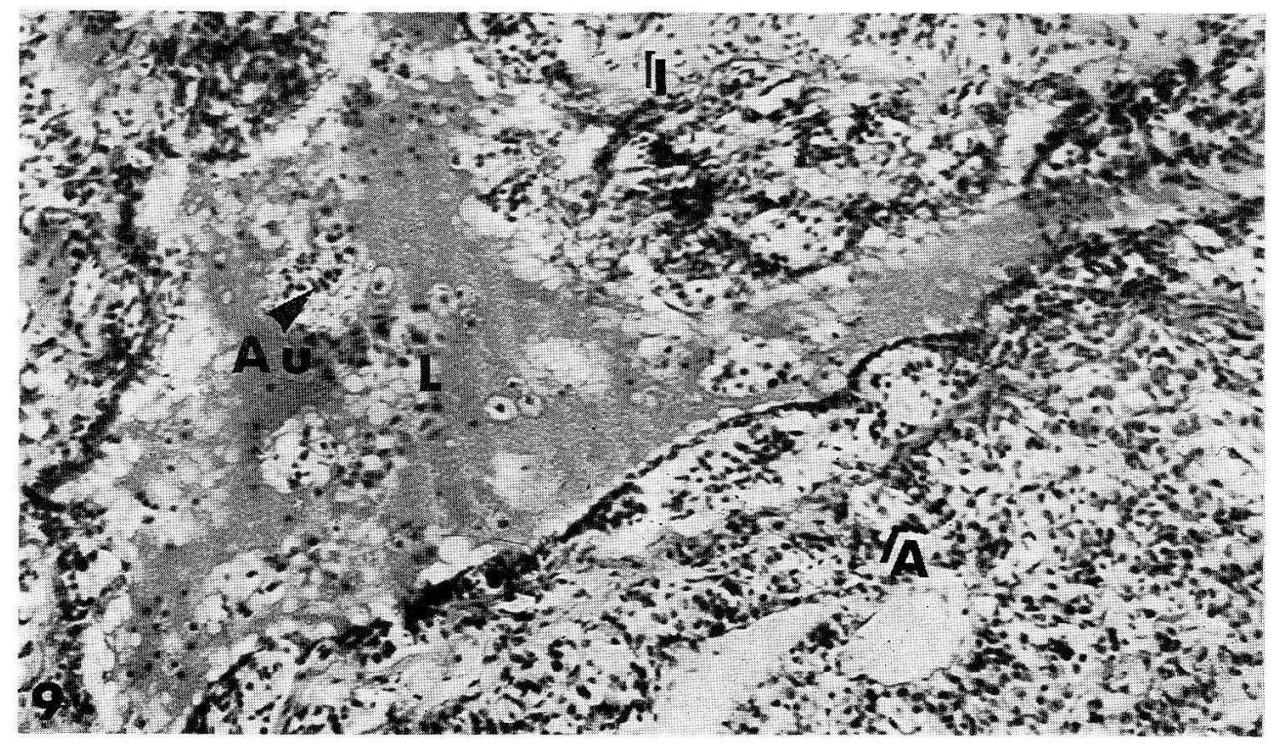

Fig. 9. Photomicrograph of a section through the bovine hypophysis showing the autolysis of intermediate lobe cells in the newly formed intraglandular lumen. Note the massive involvement of cells in the marginal zone of the intermediate lobe. The tissue was cut at $5 \mu$ and stained with hematoxylin-eosin. $A$ anterior lobe. $A u$ autolysing cells forming intraglandular colloid. $I$ intermediate lobe, $L$ intraglandular lumen. $\times 250$ 
rostral $1 / 2$ of the lobe forming the caudal boundary of the potential space. In addition the intraglandular lumen is laden with a colloid substance, the product of
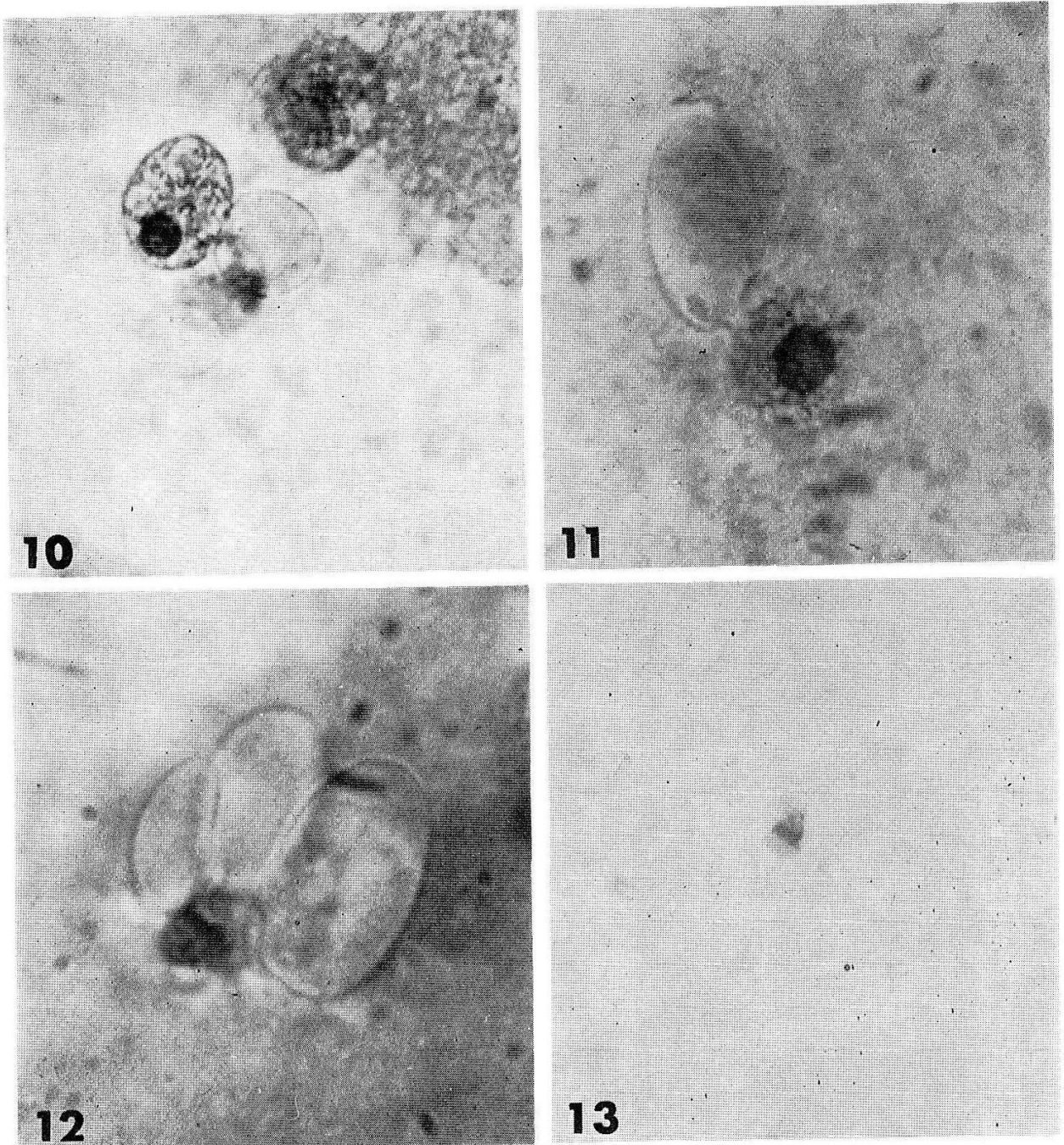

Fig. 10. Autolysis of intermediate lobe cell within intraglandular colloid. Within the intraglandular lumen, the cell continues to swell, it becomes highly vacuolated and granular in appearance. The nucleus is displaced to the surface of the cell. The section is cut at $5 \mu$ and stained with hematoxylin-eosin. $\times 5,000$

Fig. 11. Intracellular pressure causes the cell membrane to fracture and the fluid vacuoles project through the cell membrane into the lumen. The section is cut at $5 \mu$ and stained with hematoxylineosin. $\times 5,000$

Fig. 12. The cell disintegrates as the vacuoles are liberated into the intraglandular lumen. By this method, intraglandular colloid is produced. This section is cut and stained as above. $\times 5,000$

Fig. 13. With the disintegration of the cell, all that remains embedded within the colloid is its nucleus. The nucleus may be in various forms of structural disintegration. The section is cut and stained as above. $\quad \times 5,000$ 
autolyzing marginal intermediate lobe cells. These features lend credence to the activity of this lobe. More specifically, the sequence of an active and an inactive period provides a basis for dividing the cyclic behavior of the intermediate lobe into three phases. It is a choice as to whether one wishes to begin the sequence with the inactive or active phase. In this manuscript I wish to begin with the inactive phase of the cycle. The phases are: 1) resting, 2) desquamation and autolysis, and
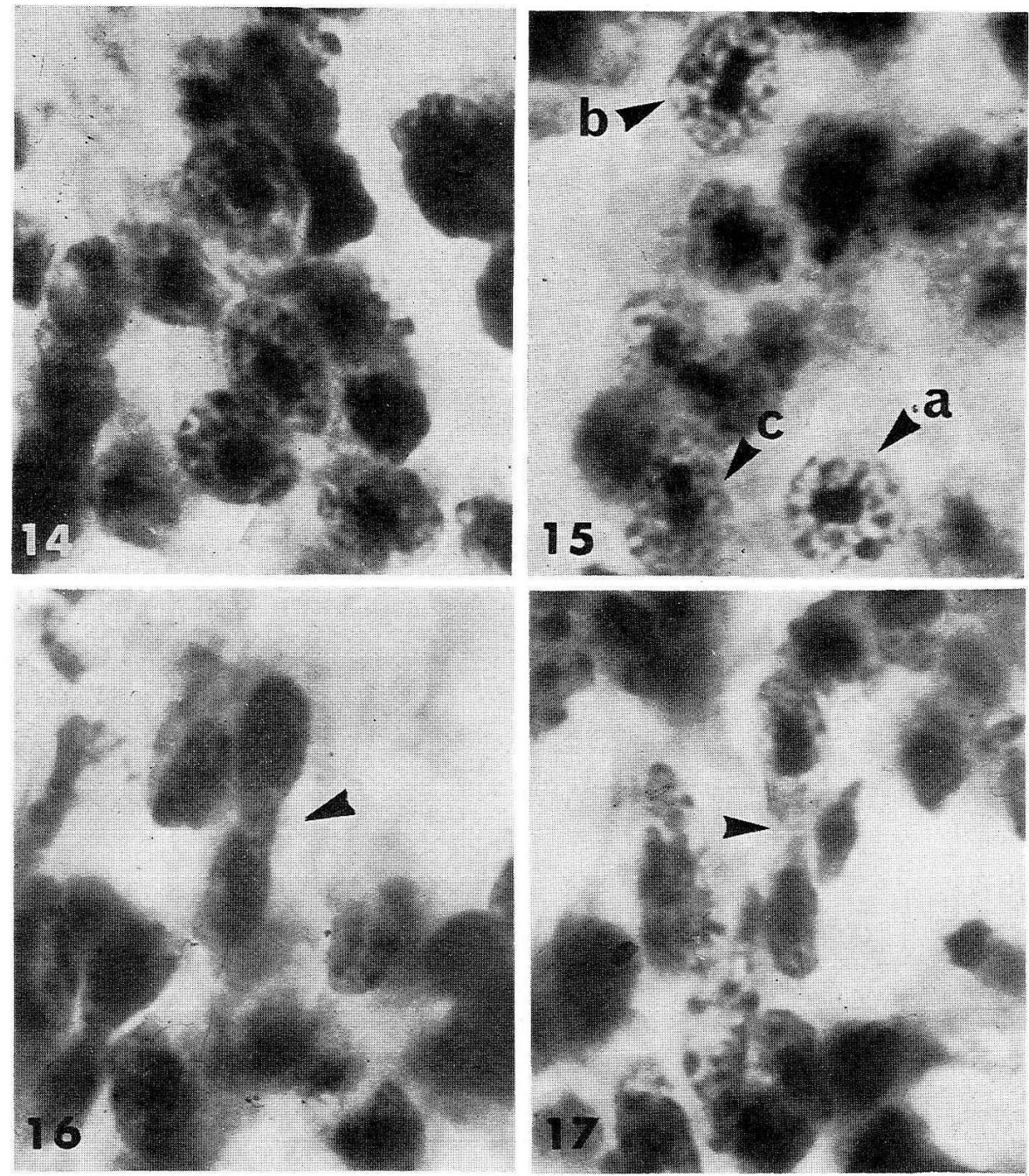

Fig 14. Intermediate lobe cells at the onset of the regenerative phase. The cells are highly granular with a centrally located nucleus. This section as well as the next 5 figures (Fig.

15-19), are cut at $5 \mu$ and stained with hematoxylin-eosin. All are magnified at $\times 5,000$

Fig. 15. The onset of the direct mode of division. Note the constriction of the nucleus in cells $a, b, c$.

Fig. 16. The cell has divided into two halves, each daughter cell gaining a nucleus.

Fig. 17. The separation of an intermediate lobe cell into two definite halves. 
3) regeneration.

During the resting phase, the anterior and the intermediate lobe are in direct contact. At this time, the cells, housed within pockets formed by dense bands of
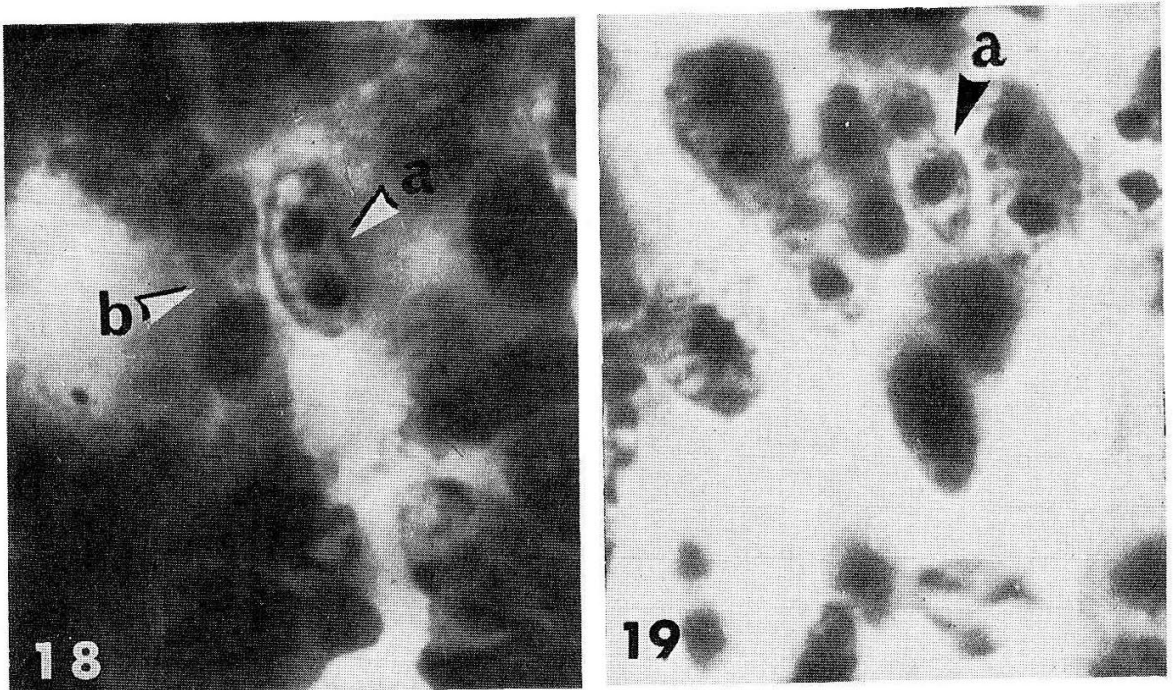

Fig. 18 and 19. The onset of the direct mode of division showing the constriction of intermediate lobe cells during the regenerative phase- $a, b$.

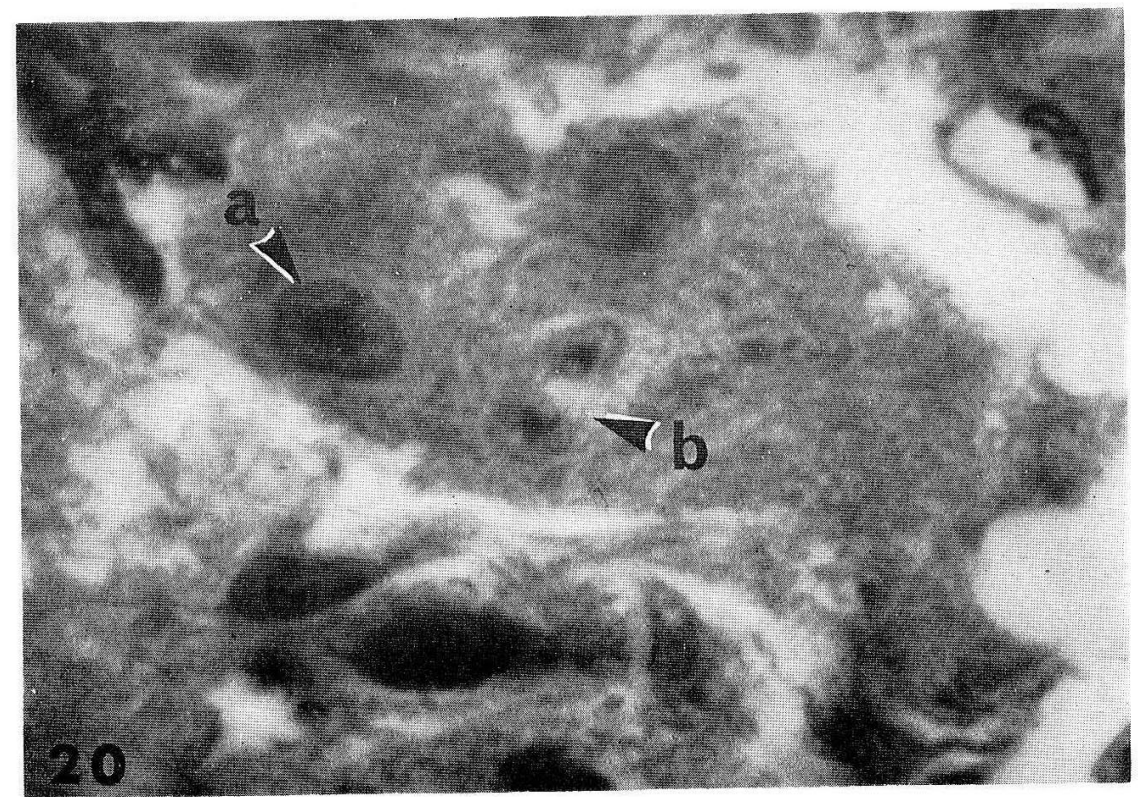

Fig. 20. Organotypic culture of intermediate lobe cells showing the onset of nuclear division $(a)$; and the direct division of a ccll into daughter components $(b)$. The section is cut at $5 \mu$ and stained with hematoxylin-eosin. $\quad \times 5,000$ 
W. H. BOYD:
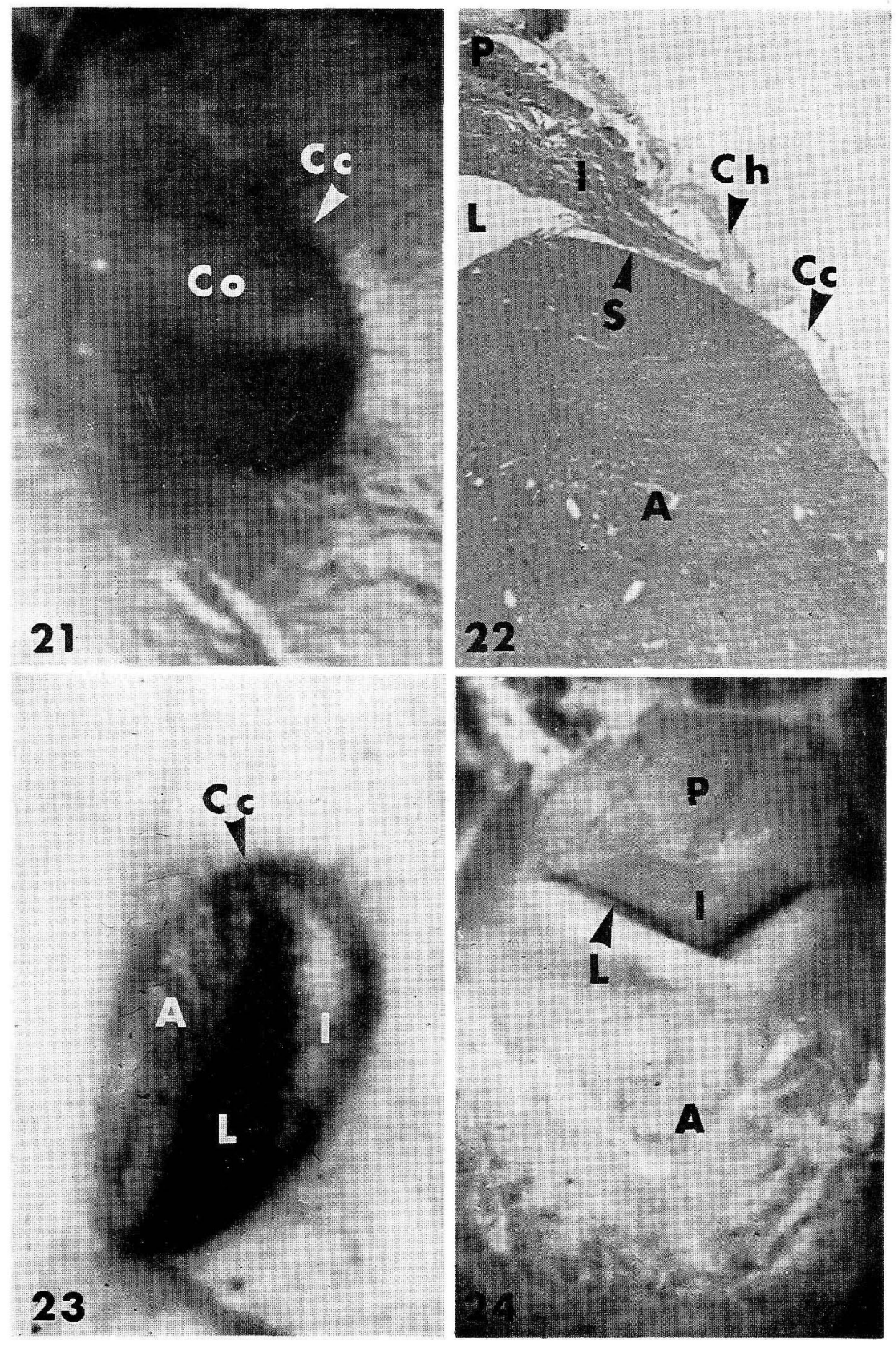
fibrous tissue, measure $0.3-0.5 \mu$ in diameter and are readily stained with hematoxylin and eosin (Fig. 5). The cells in that part of the intermediate lobe forming the floor of a recess below the diaphragma sella (Fig. 1) are more loosely arranged for they are interrupted by a continuation of the arachnoid into the gland (Fig. 6). In scattered areas throughout the lobe, intermediate lobe cells undergo a series of changes signaling the second phase, desquamation and autolysis. As this phase progresses, the scattered areas become confluent, and there is an enlargement of nearly $95 \%$ of intermediate lobe cells $(0.7-0.9 \mu)$ within the inarginal zone. In concert with these changes, the cytoplasm becomes vesicular and the fibrous tissue surrounding pockets of cells within the marginal zone undergoes degeneration. Large masses of cells desquamate, turning what was once a potential space into a sizable lumen (Fig. 8, 9). Of course, the size of the lumen varies according to the number of desquamating intermediate lobe cells at one time.

With the development of the lumen, vascular connections between the anterior and intermediate lobe are severed and the remaining intermediate lobe tissue appears rather avascular. When the lumen is turgid a significant feature is revealed. The hollowed out cords of cells and tubules observed in the most rostral portion of the intermediate lobe are seen to open directly into the upper most portion of the intraglandular lumen.

The most dramatic changes in desquamated cells occur within the newly developed lumen. Here the cells increase in size reaching a diameter of $0.10 \mu$ (Fig. 10), while the cytoplasmic vacuoles coalesce and thus increase in their diameter. Due to internal pressure the cytoplasmic vacuoles break through the cell membrane (Fig. 11) and are expelled into the intraglandular lumen. As this process continues, the breakdown of cellular materials within the lumen leads to the formation of a colloid-like substance in the form of a light yellow gell. All that remains of desquamated intermediate lobe cells is its nucleus embedded within the newly formed colloid (Fig. 13). The nucleus later disintegrates.

The intermediate lobe re-establishes itself by means of the direct division of its

Fig. 21. Bovine hypophyseal capsular cleft directly aligned with the intraglandular lumen. The photograph was taken with the gland submerged in water. Slight pressure on the gland releaves the intraglandular lumen of its colloid. $C c$ capsular cleft, $C o$ colloid. $\times 700$

Fig. 22. Photomicrograph of a section taken through the capsular cleft shown in Figure 21 . The intraglandular lumen is not completely engorged with colloid, for a portion of the potential space between the anterior and intermediate lobe remains. Note that the potential space is directed towards the capsular cleft. $A$ anterior lobe, $C c$ capsular cleft, $C h$ dural capsule of the hypophysis, $I$ intermediate lobe, $L$ intraglandular lumen, $P$ posterior lobe, $S$ potential space. The section is cut at $7 \mu$ and stained with hematoxylin-eosin. $\quad \times 140$

Fig. 23. Bovine hypophyseal capsular cleft directly aligned with the intraglandular lumen. In a condition such as this, the intraglandular lumen is engorged with colloid and the lumen opens directly at the capsular cleft. Note the pouting of the anterior and intermediate lobe in the orifice of the cleft. $A$ anterior lobe, $C c$ capsular cleft. $I$ intermediate lobe, $L$ intraglandular lumen. The whole gland was stained with a mixture of acid fuchsin and methy. lene blue. $\times 700$

Fig. 24. Photograph of the bovine hypophysis viewed from below. The hypophyseal capsule covering the base of the gland has been removed to demonstrate how the intraglandular lumen opens onto the capsule of the gland when it is engorged with colloid. Figures 23 and 24 are photographs of the same gland. $A$ anterior lobe, $I$ intermediate lobe, $L$ intraglandular lumen, $P$ posterior lobe. $\times 45$ 
remaining cells (Fig. 14), the third phase of the cycle. Cellular division is accomplished by a separation of the nucleus into two segments (Fig. 15). As the segments move away from one another, the cell elongates (Fig. 16-19). Cleavage of the cell ensues; each daughter cell gaining a portion of the original nucleus. An organotypic culture of small aggregates of intermediate lobe tissue in a balanced media (CMRL$\mathrm{H}-597$, Connaught Medical Research Laboratories, Toronto, Canada) demonstrates direct cellular division (Fig. 20).

Re-establishing the intermediate lobe has three major effects. First, it prepares the lobe for the onset of the next cycle; second, there is a renewal of a potential space between the lobes, and third, vascular connections are re-established between the anterior and intermediate lobe.

With the re-establishment of the intermediate lobe, the contents of the intraglandular lumen are pushed into the venous cavernous sinuses by way of well defined capsular clefts (Fig. 21-23). Capsular clefts are directly aligned with the intraglandular lumen and pass through the lower lateral and basal portion of the interglandular sulcus, a superficial landmark in the capsule between the anterior and the intermediate lobe. The clefts are easily located with a hand lens and differ from capsular clefts draining venous blood into the cavernous sinuses not only because of their location and size, but because they are not guarded at their exit by a valve-like flap formed by the capsular dura.

Even though the lumen may not be completely filled with colloid, slight pressure on the gland will help to expell the contents of the lumen into the cavernous sinus (Fig. 21). Under these conditions, the colloid is pushed between the anterior and the intermediate lobe towards a capsular cleft (Fig. 22). When the intraglandular lumen is engorged with colloid, the lumen opens directly upon the capsule (Fig. 23, $24)$, and the colloid has free access to the venous circulation of the cavernous sinuses by way of capsular clefts.

\section{Discussion}

Although the intermediate lobe in the human subject as well as in several experimental animals were studied, that in the cow exemplifies the more salient anatomical features directly associated with intermediate lobe activity and common to all hypophyseal glands in which three lobes can be distinguished.

Important enough to consider briefly, is the relationship between the intermediate lobe and the subarachnoid space observed in the present study. This feature is readily demonstrable in bovine, but less so in the other glands studied. Colloid filled tubules and hollowed out cords of cells found mainly in the upper $1 / 3$ of the intermediate lobe, that part of the intermediate lobe forming the floor of the subarachnoid space surrounding the hypophyseal stalk, are directed on the one hand towards the subarachnoid space, and on the other, open into the intraglandular lumen. These findings immediately raise the question of a possible contribution of either glandular materials to cerebro-spinal fluid or cerebro-spinal fluid to the intermediate lobe or to the contents of the intraglandular lumen. Some credence can be given the latter possibility for relevant literature (SLOPER et al., 1960) reports a marked uptake of methionine by the intermediate lobe following subarachnoid injections. It is interesting that similar intermediate lobe tubules under a variety 
of names have been recognized by earlier workers (Cushing and GoETsh, 1910; VANDERBuRGH, 1917; Lewis and LeE, 1927; RASMUSSEN, 1928) who associate these structures with either the posterior lobe or the intermediate lobe.

The lengthy discussion as to the existence or non-existence of the remains of Rathke's pouch (RASMUSSEN, 1928; SELYe, 1943) will not be made an issue here. The heretofore unrecognized cyclic behavior of the intermediate lobe has led to the confusion. There is, indeed, in all of the glands studied, a potential space between the anterior and the intermediate lobe which could very well be the remains of Rathke's pouch. This space is an all inportant feature, for it plays an essential role in intermediate lobe activity.

During the resting phase of the intermediate lobe, the anterior and intermediate lobe are closely opposed and the only suggestion of a potential space is the characteristics of the cells lining the opposing walls. The rostral wall of the space, that is, the caudual border of the anterior lobe, is lined by one or two layers of cuboidal to columnar type cells resting on a basement membrane. The caudal wall of the space is lined by intermediate lobe cells.

Most investigators report that the intermediate lobe is virtually avascular (VAnderburgh, 1917; Kurosumi et al., 1961; Howe and Maxwell, 1966) and the source of its nutritive supply is not clear. DANIEL and PRICHARD (1956) reported that the blood supply of the intermediate lobe is derived from the short portal vessels of the posterior lobe. This is, indeed, partially true. Understanding the vasculature of the intermediate lobe depends upon knowledge of its cyclic behavior and the formation of the intraglandular lumen. Basically, the vasculature of the three lobes are interconnected when the gland is in the resting phase and the anterior and intermediate lobe are in direct contact. It is interesting that vascular buds from the intermediate lobe grow into the anterior lobe during this phase thus affording a complete circulation through the gland. Indeed, mitosis of vascular endothelial cells occur. In this regard, it is interesting that Duchen (1962) recognized mitosis among endothelial cells of vessel walls in the posterior lobe of the hypophyses in the rat.

With the development of the colloid filled intraglandular lumen, the vascular connections between the anterior and intermediate lobe are severed. Some proof of this temporary breakdown of blood vessels is that blood cells may be found in the intraglandular colloid, an observation also reported by JuBb and McENTEE (1955). During this period, the intermediate lobe is dependent solely upon the posterior lobe for its blood supply. Although this temporary supply is apparently sufficient, the lobe, nonetheless, appears rather avascular. This condition is releaved when the intermediate lobe is re-established and the vascular relationship between the anterior, intermediate and posterior lobe is renewed.

The present study demonstrates that the cyclic behavior of the intermediate lobe, at least in bovine, involves the function of a single cell. This finding is not in keeping with relevant literature (Romeis, 1940, Kurosumi et al., 1961; Duchen, 1962; Howe and Maxwell, 1966; Howe and Thody, 1967, 1969a, b; Raftery, 1969) for the intermediate lobe has always been thought to be composed of two different cell types. Even in this light, RAFTERY (1969) held some reservations regarding the two cell concept with morphological differences between these cells. He further questioned whether these cells may not, indeed, be modifications of a common intermediate lobe 
cell. Furthermore, Duchen (1962) presented a report on the rat in which he categorically stated that the changes which he describes with reference to two intermediate lobe cells represent different states of function in the same cell. In general, the cells recognized under the light microscope as type 1 are round to elongated, with a clearly defined cell membrane, a large volume of vacuolated watery clear granular cytoplasm, and a prominent nucleolus. The type 2 cells are thought to be smaller than type 1 , irregular in outline, with dark staining cytoplasm due to closely packed small particles and with a round to elongated hyperchromia nucleus. From the description of type 1 and type 2 intermediate lobe cells, the type 2 cell simulates that observed during the resting phase of the cycle as presented in this study, while the type 1 cell simulates those observed during the active phase of the cycle. It is important to record that in bovine, the marginal zone is made up entirely of cells from the intermediate lobe. This finding is in sharp contrast to those reporting a definite layer of cells and a basement membrane in this location (Kurosumi et al., 1961). Furthermore, ciliated cells are reported in the marginal zone (BRYANT, 1916; VANDERburgh, 1917; Rasmussen, 1928; Kurosumi et al., 1961) an observation that could not be confirmed in either the present study or those made by TRAUTMAN (1909) on a large series of animals.

Since studies of the general anatomy of the intermediate lobe produced only a limited amount of information regarding its activity, investigators (SELYE, 1943; Duchen, 1962; Legait and Legait, 1963; Ziegler, 1963; Soboleva, 1964) resorted to an experimental approach which involved the ingestion of hypertonic saline by rats. This resulted in cellular changes thought to represent alterations in the function of the intermediate lobe. The cellular changes involved type 2 cells, those simulating resting cells in the present study. Under experimental conditions, these cells increase in number leading to the speculation that they represent a transitional form between type 1 and type 2 cells. These events supposedly occur without some form of cell division. Microscopic observations of specific type intermediate lobe cells have not been confirmed histochemically for pertinent literature reports some difficulty in differentiating cell types by these methods. Furthermore, these data show that enzyme activity is not uniform throughout the tissue (HowE and THODY, 1967; RAFTERY, 1969).

In the light of the present findings; cyclic behavior of the intermediate lobe, formation of the intraglandular lumen, colloid formation, direct division of intermediate lobe cells etc., it is interesting that reports on experimental studies do not present similar information. Strangely enough, an early paper by SELYE (1943) relates intraglandular colloid to degenerative changes in the basophils of the anterior lobe rather than to intermediate lobe cells. In bovine, all intraglandular colloid was of intermediate lobe origin and only infrequently were cells from the anterior lobe observed migrating through the well defined layer of cells forming the caudal border of the anterior lobe into the intraglandular lumen.

Althogh most investigators agree that intraglandular colloid is of intermediate lobe origin (Crowe et al., 1910; VAnderburGh, 1917; RAsmussen, 1928; Kurosumi et al., 1961 and others), none describe the drainage of the colloid from the intraglandular space. BRANDER (1932) credits HALLER (1808) with the suggestion that the intraglandular space opens into the cranial venous sinuses, but it was BRANDER who first 
noticed a "gap" in the capsule of the human hypophysis leading into a channel which terminates in relation to the lower extremity of the intraglandular lumen. BRANDER recognized intraglandular colloid in the lumen of the human hypophysis and stated, "that the passage of colloid by a duct directly into the blood stream introduces a novel physiological concept." Indeed, the present study confirms BRANDER's early observations and now attention can be directed towards the effect of intraglandular materials in the circulation.

As early as 1927, LEwIs and LEE reported that intermediate lobe colloid of the intraglandular lumen was active only when there was desquamation or autolysis of intermediate lobe cells in the colloid. The result of this activity was a pressor effect. Since the investigations by Atwell (1919), Hogben and Winton (1922) and Sмiтн and Sмiтн (1923), the intermediate lobe has been associated with the melanocyte stimulating hormone. Studies by KRIvoY and GuILlEmin (1961) show a neurohumoral action of MSH, while recent studies by Boyd (1970a, b, c, d; 1971) show that its cyclic behavior is associated with erythropoiesis. In addition, a functional relationship between the intermediate lobe and $\mathrm{ACTH}$ has been reported by GosBEE et al. (1970).

Although reported previously in other expermental animals (ENEMAR and FLACK., 1965; Iturriza and Mestorino, 1965; SAland, 1967), the relationship between the bovine intermediate lobe and the hypothalamus warrants a separate paper. Suffice to say at present that nerve endings ramifying amongst intermediate lobe cells in the caudal $1 / 2$ of the intermediate lobe have been traced to the hypothalamus (unpublished data). Indeed, this information strongly suggests that intermediate lobe activity may be initiated and controlled by the hypothalamus by a feedback mechanism similar to that proposed by MORLEy and StoHlman (1969).

As the present investigation of the intermediate lobe progresses, there are strong indications that cellular changes involve a broad spectrum of intricate controlling mechanisms not inherent in the cell per se. When the mechanisms are challenged, they direct their activity towards large groups of cells which either die, or proliferate and differentiate along lines beneficial or lines injurious to bodily function Investigating these mechaniasms form the basis for future cellular studies.

\section{References}

Arvy, L. et F. Du Boisson: L'hypophyse de Sus scrofa L. var. domestique. C. r. Séanc. Soc. Biol. 155: 2123-2126 (1961).

Atwell, W. J.: On the nature of the pigmentation changes following hypophysectomy in the frog larva. Science 49: 48-52 (1919).

Balogh, K. and R. B. Cohen: Histochemical localization of oxidative enzyme systems in the human anterior pituitary. Endocrinology 70: 874-880 (1962).

Boyd, W. H.: The effect of bovine hypophyseal intermediate lobe tissue and colloid on microglia. J. Neurovisc. Relat. 31: 382-386 (1970a).

-: Proliferation of glomerular capillary endothelial cells under the influence of hypophyseal intermediate lobe materials. Z. Anat. Entwickl. Gesch. 130: 306-315 (1970b). 
Boyd, W. H.: Transformation of hepatic reticuloendothelial cells to erythroid cells by pars intermedia. Amer. J. Physiol. 219: 1614-1619 (1970c).

-: Influence of hypophyseal intermediate lobe tissue and colloid on the reticuloendothelial cells of the liver. Experientia 26: 72-74 (1970d).

Boyd, W. H.: A chamber for organotypic culture: Adapted for growing large volumes of tissue. Stain Technol. 46: 85-87 (1971).

Brander, J.: The intraglandular cleft of the pituitary body and its connections. J. Anat. (Lond.) 66: 202-209 (1932).

Bryant, W. S.: Sensory elements in the human cerebral hypophysis. Anat. Rec. 11: 25-27 (1916).

Crowe, S. J., H. Cushing and J. Homans: Experimental hypophysectomy. Bull. Johns Hopkins Hosp. 21: 127-131 (1910).

Cushing, H. and E. Goetsch.: Concerning the secretion of the infundibular lobe of the pituitary body and its presence in the cerebrospinal fluid. Amer. J. Physiol. 27: 60-68 (1910).

Daniel. P. M. and M. M. L. Prichard: Anterior pituitary necrosis. Infarction of the pars distalis produced experimentally in the rat. Quart. J. exp. Physiol. 41: 215-225 (1956).

Duchen, L. W.: The effects of ingestion of hypertonic saline on the pituitary gland in the rat: A morphological study of the pars intermedia and posterior lobe. J. Endocrinol. 25: 161-168 (1962).

Enemar, A. and B. Flack: On the presence of adrenergic nerves of the pars intermedia of the frog, Rana temporaria. Gen. comp. Endocrinol. 5: 577-583 (1965).

Gosbee, J. L., J. Kraicer, A. Kastin and A. Schally: Functional relationship between the pars intermedia and ACTH function in the rat. Endocrinology 86: 560-567 (1970).

Haller, B.: Untersuchungen über die Hypophyse und die Infundibularorgane. Morphol. Jahrb., Bd. 25. A. 101: 1-30 (1896).

Hogben, L. T. and F. R. Winton: The pigmentary effector system. I. Reaction of frog's melanophores to pituitary extracts. Proc. Roy. Soc. B. 93: 318-325 (1922).

Howe, A. and D. Maxwell: An electronmicroscopic study of the pars intermedia of the pituitary gland in the rat. J. Physiol. (Lond.) 183: 70-76 (1966).

Howe, A. and A. J. Thody: Histochemical demonstration of oxidative enzymes in the adenohypophysis of the pig, with particular reference to the pars intermedia. J. Endocrinol. 39: 351-358 (1967).

: The effect of hypothalamic lesions on the melanocyte-stimulating hormone content and histology of the pars intermedia of the rat pituitary gland. J. Physiol. (Lond.) 210: 25-26P (1969a).

The effect of hypothalamic lesions on the melanocyte-stimulating hormone content and histology of the pars intermedia of the rat pituitary gland. J. Physiol. (Lond.) 203: $159-171$ (1969b).

Iturriza, F. C. and M. Mestorino: Nervous fibers in the pars intermedia of the toad, Bufo arenarum. Acta anat. 60: 398-405 (1965).

Jubb, K. V. and K. McEntee: Observations on the bovine pituitary gland. II. Architecture and cytology with special reference to basophil cell function. Cornell Vet. 65: 593-641 (1955).

Kastin, A. J.: $\mathrm{MSH}$ and vasopressin activities in pituitaries of rats treated with hypertonic saline. Fed. Proc. (Fed. Amer. Soc. Exp. Biol.) 26: 255-260 (1967).

Krivoy, W. A. and R. Guillemin: On a possible role of melanocyte stimulating hormone (B-MSH) in the central nervous system of the mammalia. An effect of B-MSH in the spinal cord of the cat. Endocrinology 69: 170-179 (1961).

Kurosumi, K., T. Matsuzawa and S. Shibasaki: Electron microscope studies on the fine structure of the pars nervosa and pars intermedia, and their morphological interrelation in the normal rat hypophysis. J. comp. Endocrinol. 1: 433-452 (1961).

Legait, H. and $\mathbf{E}$. Legait: Relationship between the hypothalamus and pars intermedia in some mammals and amphibians. Mem. Soc. Endocrinol. 12: 165-185 (1962).

Lewis, D. and F. C. Lee: On the glandular elements in the posterior lobe of the human hypophysis. Bull. John Hopkins Hospital 61: 241-269 (1927). 
Lewis, D., J. L. Miller and S. A. Methews: The effects on blood pressure in intravenous injections of extracts of the various anatomical components of the hypophysis. Arch. Int. Med. 7: 785-791 (1911).

Morley, A. and F. Stohlman: Erythropoiesis in dog: The periodic nature of the steady state. Science 165: 1025-1027 (1969).

Pearse, A. G. E. and S. van Noorden: The functional cytology of the human hypophysis. Endocrinology 12: 129-150 (1963).

Raftery, A. T.: Enzyme histochemistry of the pars intermedia of ox pituitary gland. J. Anat. 105: 307-315 (1969).

Rasmussen, A. T.: The morphology of pars intermedia of the human hypophysis. Endocrinology 13: 129-150 (1928).

Romeis, B.: Hypophyses. In: Möliendorffs Handbuch der mikroskopischen Anatomie des Menschen. VI/3. Berlin, Springer Verlag, 1940.

Romieu, M., A. Stahl et R. Serte: Les phosphatases alcolines dans l'hypophyse du chat. Etude histochemiques. C. r. Séanc. Soc. Biol. 145: 415-416 (1951).

Saland, I. C.: Ultrastructural differences in cells of pars intermedia of light and dark-adapted frogs. Anat. Rec. 157: 314-320 (1967).

Selye, H.: Experiments concerning the mechanism of pituitary colloid secretion. Anat. Rec. 86: 109-119 (1943).

Sloper, J. C., D. J. Arnott and B. C. King: Sulphur metabolism in the pituitary and hypothalamus of the rat: A study of radioisotope-uptake after the injection of ${ }^{35} \mathrm{~S}$ DL-cysteine, methionine, and socium sulphate. J. Endocrinol. 20: 9-23 (1960).

Smith, P. E. and I. P. Smith: The response of the hypophysectomised tadpole to the intraperitoneal injection of the various lobes and colloid of the bovine hypophysis. Anat. Rec. 25: 150-162 (1923).

Soboleva, E. L.: The pars intermedia of the hypophysis during salt loading. Bull. exp. Biol. Med U.S.S.R. 55: $577-580$ (1964).

Trautman, A.: Anatomie und Histologie der Hypophysis cerebri einiger Säuger. Arch. mikrosk. Anat. 74: 95-112 (1909).

Vanderburgh, C. M.: The hypophysis of the guinea pig. Anat. Rec. 12: 95-112 (1917).

Ziegler, B.: Licht- und elektronenmikroskopische Untersuchungen an Pars intermedia und Neurohypophyse der Ratte. Z. Zellforsch. 59: 486-506 (1963).

Professor Dr. William H. Boyd

Department of Biomedical Sciences

University of Guelph

Guelph, Ontario, Canada 